\title{
Social cues in the expression of sequential alternative reproductive tactics in young males of the peacock blenny, Salaria pavo
}

\author{
Teresa Fagundes a , Mariana G. Simões ${ }^{\text {a,b }}$, David Gonçalves ${ }^{\text {a,c,d,* }}$, Rui F. Oliveira ${ }^{\text {a,e }}$ \\ a Unidade de Investigação em Eco-Etologia, ISPA-IU, Rua do Jardim do Tabaco, 34, 1149-041 Lisboa, Portugal \\ b Instituto de Medicina Molecular, Faculdade de Medicina da Universidade de Lisboa, Av. Professor Egas Moniz, 1649-028 Lisboa, Portugal \\ c Centro de Ciências do Mar (CCMAR-CIMAR), Universidade do Algarve, Campus de Gambelas, 8005-139 Faro, Portugal \\ ${ }^{\mathrm{d}}$ University of Saint Joseph, Rua de Londres 16, Macau \\ e Champalimaud Neuroscience Programme, Instituto Gulbenkian de Ciência, Rua da Quinta Grande, 6, 2780-156 Oeiras, Portugal
}

\section{A R T I C L E I N F O}

\section{Article history:}

Received 19 March 2012

Received in revised form 18 July 2012

Accepted 29 July 2012

\section{Keywords:}

Alternative reproductive tactics

Social dominance

Androgens

11-Ketotestosterone

Cortisol

Body condition

\begin{abstract}
A B S T R A C T
Phenotypic change in response to variation in environmental cues has been widely documented in fish. Transitions in social dominance, in particular, have been shown to induce a rapid switch in reproductive phenotypes in many species. However, this effect has been mainly studied in adults and focused on behavioural transitions. The way social cues constraint the phenotypic development of juveniles remains poorly studied in fish. We tested the importance of social dominance and density in the phenotypic development of juveniles of the peacock blenny Salaria pavo. This species shows sequential male alternative reproductive tactics. In the first breeding season males can reproduce as nest-holders or as parasitic males (female-mimicking), or postpone reproduction; from the following season afterwards all males reproduce as nest-holders. Parasitic males have relatively larger testes that lack a testicular gland, present in the testes of nest-holders. The testicular gland is the main source of androgens in the testes and accordingly nest-holders have higher circulating androgen levels. In addition, exogenous androgen administration to parasitic males promotes the development of secondary sexual characters (SSC) only present in nest-holders such as a head crest and an anal gland. We raised juveniles under a high or low-density treatment and monitored social interactions for 1 month. No significant effect of density on the development of juvenile males was detected. However, within each replicate, the relative body size of juvenile males at the beginning of the experiment determined their dominance status, with dominant males developing towards the nest-holder morphotype. Dominant males engaged in more nest defence behaviour, showed larger testicular glands, had higher levels of 11-ketotestosterone (11-KT) and testosterone (T) and developed more SSC, as compared to subordinate males. However, these effects of social dominance were moderated by body condition as only dominant males in good body condition developed SSC. The effect of social dominance and of the area of the testicular gland on the development of SSC was mediated by 11-KT and on the expression of nest defence behaviour by T. Interestingly, in spite of the higher androgen levels and more pronounced morphologic development of SSC in dominant individuals, gonadal development was independent of social dominance and most fish still had underdeveloped testis at the end of the experiment. In conclusion, social dominance promoted the development of the testicular gland, an increase in circulating androgen levels and the development of SSC, but did not promote testicular development. This suggests a dissociation of mechanisms underlying sexual maturation and the expression of male reproductive traits. This dissociation seems to be the key for the occurrence of female-mimicking males in this species, which are sexually mature despite lacking the SSC typical of nest-holders.
\end{abstract}

(C) 2012 Elsevier Inc. All rights reserved.

\section{Introduction}

Alternative reproductive tactics (ART) may be determined by environmental factors when these are good predictors of the reproductive

\footnotetext{
* Corresponding author at: Unidade de Investigação em Eco-Etologia, ISPA-IU, Rua do Jardim do Tabaco, 34, 1149-041 Lisboa, Portugal. Tel.: + 35121 8811700; fax: + 35121 8860954.

E-mail address: davidg@ispa.pt (D. Gonçalves).
}

success of each of the tactics [1]. Some social cues have been demonstrated to promote the expression of different ART. Social dominance, for instance, has recently been demonstrated to promote the rapid development of gonads and concomitant switch from helper to breeding tactic in the cooperatively breeding cichlid Neolamprologus pulcher [2]. Similarly, Astotilapia burtoni quickly changes its reproductive phenotype in response to social dominance through up regulation of production of GnRH and androgens which promote sexual maturation, courting behaviour and sexual coloration [3]. However, the reproductive phenotypes of 
these two species are reversible and do not involve morphological changes. Animals expressing ART very often differ morphologically. The typical pattern of ART consists of two types of males that are characterized by different sets of traits: on the one hand bourgeois [4], type I [5] or dominant males [6]; and, on the other hand, parasitic, type II or subordinate males. The bourgeois males invest in obtaining and defending resources by being territorial and attracting females. They are typically larger and commonly exhibit morphological differences like secondary sexual characters (SSC). Parasitic males rely on behaviours like sneaking, darting or female-mimicking in order to fertilize eggs during spawning events between the females and the bourgeois males, thus exploiting the reproductive investment of bourgeois males. In general, parasitic males have relatively larger gonads than bourgeois males to overcome the disadvantage of a lower proximity to females when spawning [4]. Despite the typical sets of traits of ART, different combinations of those traits are found in different species and physiological mechanisms should vary accordingly to provide such variability. Therefore, we investigated which cues may trigger the expression of one or another tactic in juveniles of the peacock blenny Salaria pavo and what physiological mechanisms modulate the corresponding reproductive phenotype.

Mechanisms underlying tactic expression should be able to convert environmental cues into appropriate reproductive behaviours and morphological traits such as SSC. In fish, androgens, and particularly 11-ketotestosterone (11-KT), are known to promote the development of SSC [7] and to influence the expression of male reproductive behaviours [8]. Moreover, social environment modulates androgen levels in teleost fish $[9,10]$. Therefore, we expect that social dominance promotes the development of morphological and behavioural traits typical of the bourgeois tactic and that this effect on development is achieved via modulation of androgens (mediation effect, sensu Baron and Kenny [11]). More attention has been given recently to the possible mediation or moderation (sensu Baron and Kenny [11]) roles of corticosteroids on the effect of factors of the social environment on reproductive phenotype expression (e.g. [12-14]). The response of corticosteroids to social dominance varies widely in different species, but in some fish species social dominance influences cortisol levels (e.g. subordinate males have higher cortisol levels in coho salmon, Oncorhynchus kisutch [15]; and in rainbow trout, Oncorhynchus mykiss [16]). Cortisol, in turn, can modulate androgen production [17] and therefore it should influence the expression of the reproductive phenotype. In this way, cortisol may mediate the effect of social dominance on the expression of reproductive tactics. But corticosteroids have also been proposed to interact with the reproductive endocrine axis by suppression of androgen receptors or by competing with binding globulins or steroidogenic enzymes [18]. Such an effect, in species where cortisol is not dependent on social dominance, may constitute a moderation effect, i.e., the expression of the reproductive phenotype may depend on social dominance but levels of corticosteroids may alter this relationship.

Contrary to what has been the norm, in which species with fixed alternative tactics are usually tested in early stages of development (e.g. $[19,20]$ ) and species with sequential tactics have been tested only during the switch between tactics (e.g. [21]), here we explore the possible mechanisms of tactic determination at the onset of reproduction thus, from the juvenile stage to the first reproductive morph. At this life stage, the endocrine mechanisms have been overlooked in species with sequential alternative tactics and very much so in vertebrates. Hence, we address the following questions: Can social dominance and male density influence tactic expression? And can social dominance also influence slower developing reproductive morphotypes such as those that involve SSC? What are the physiological mechanisms underlying the expression of such conditional tactics? We explore the role of steroid hormones as possible mediators or moderators of the effects of social dominance on the expression of tactic-specific traits. We expect that (1) social dominance may constitute a cue to tactic expression since higher social dominance facilitates resource acquisition and can therefore contribute to the reproductive success of the resource defending tactic, the bourgeois tactic; (2) social dominance should promote the expression of the bourgeois tactic through higher levels of androgens and/or lower levels of cortisol; (3) male density, as a potential signal of the intensity of male-male competition, should raise the incidence of the parasitic tactic.

\section{Materials and methods}

\subsection{Model species}

Two male ART are present in S. pavo. Parasitic males are small males who reproduce by fertilizing eggs inside the nests defended by nest-holders [22,23]. Nest-holders are larger males that establish and defend nests (bourgeois tactic). They express SSC, namely a head crest and a pheromone producing anal gland [24-26] and they have higher levels of both testosterone (T) and 11-KT than parasitic males [27,28]. Parasitic males deceive nest-holders through female mimicry [23,29], displaying female-like courtship towards nest-holder males and not expressing SSC. They have relatively larger testes than nest-holders and undeveloped testicular glands [23]. The testicular glands are accessory organs of the gonads and constitute the major source of androgens in this species [27,30]. In the first year males can either express 1 ) the parasitic tactic; 2) the nest-holder tactic; or 3) postpone reproduction, and all males will reproduce as nest-holders from their second breeding season onwards [31] (T. Fagundes, M. G. Simões, J. L. Saraiva, A. F. H. Ros, D. Gonçalves and R. F. Oliveira, unpublished data).

\subsection{General procedures and sampling}

Juvenile males of $S$. pavo were captured during low tide in the intertidal area of Ilha da Culatra, a barrier island situated in Ria Formosa Nature Park $\left(36^{\circ} 59^{\prime} \mathrm{N}, 7^{\circ} 51^{\prime} \mathrm{W}\right)$, in the South coast of Portugal. We sampled artificial hard substrates such as tiles and bricks, existent in the area to delimit the borders of clam culture fields, and captured juveniles with hand nets. Fish were collected prior to the beginning of the reproductive season and were identified as individuals without SSC, that exhibited a male genital papilla and that did not release milt when pressing the ventro-lateral surface of the abdomen. In previous studies, where fish were dissected for gonadal inspection, milt stripping has been verified to be an appropriate criterion to distinguish parasitic males from non-reproductive males [32].

After capture, fish were transported to the aquarium facilities of the ISPA-IU in Lisbon and housed in a stock tank (length: $120 \mathrm{~cm} \times$ width: $40 \mathrm{~cm} \times$ height: $50 \mathrm{~cm}$ ) with sand and shelters. The light:dark cycle and the temperature in the stock tank, as well as in the treatment aquaria, were $13 \mathrm{~L}: 11 \mathrm{D}$ and $24.5 \pm 1{ }^{\circ} \mathrm{C}$, respectively. These conditions are similar to those experienced by this population in the field during this time of the breeding season. In previous experiments it was shown that this species exhibits the full range of behaviours, including male and female courtship displays and egg laying, under similar conditions (e.g. [29,32-35]). Fish were fed ad libitum once a day with chopped mussel's flesh. Fish remained in the stock tank from 1 to 2 weeks before being assigned to a treatment aquarium. Just before the start of the experiment fish were anaesthetized with MS-222 (PHARMAQ Ltd, dilution $1: 10,000)$ and measured with a $0.1 \mathrm{~mm}$-precision calliper for total length (TL) and maximum head height. The length and width of the anal gland were measured with a $20 \times$ magnifier to the nearest $0.1 \mathrm{~mm}$ (SZ-PT Olympus stereoscope). The body weight was measured on a $0.001 \mathrm{~g}$-precision scale. Fish recovered from the anaesthesia in a container with abundant aeration and were then introduced in the treatment aquaria. In the last day of the experiment, fish were euthanized with an overdose of MS-222 (dilution 3:10,000; American Veterinary Medical Association 2007). Immediately after the anaesthesia, blood samples were collected from the caudal vein with a $1 \mathrm{ml}$ heparinised syringe and a 25 gauge needle. The blood sample was centrifuged at $3000 \mathrm{rpm}$ 
for $10 \mathrm{~min}$ and the plasma was stored at $-20^{\circ} \mathrm{C}$ until further processing. At the end of the experiment the measurements taken at the beginning of the experiment were repeated. Additionally, length and width of testes and of testicular glands, and wet weight of body after removal of internal organs (eviscerated body weight) and of testes were measured.

\subsection{Experimental treatment}

The experiment was conducted between mid April and May of 2003 and 2004. The experimental period included 2 weeks of the pre-reproductive season and extended another 2 weeks into the reproductive season. Young males from which sperm can be stripped are present in the field at the start of the breeding season suggesting that the onset of the expression of the tactics occurs either during or before this early period. Thus, the period in which the experiment was carried out was selected in order to maximize the probability of including a potential sensitive period and a period during which the reproductive tactics can be expressed and identified. The one month duration of the experimental period allowed the subjects (juvenile males at the start of the experiment) to express their reproductive tactic in the current breeding season. Males could differentiate SSC and breed as a nest-holder, invest only in spermatogenesis and breed as a parasitic male, or postpone breeding and allocate resources into growing until the next breeding season.

Juvenile fish were introduced in their treatment aquaria simultaneously after morphological measurements. The high density treatment consisted of 6 juvenile males per aquarium and the low density treatment of 3 juvenile males per aquarium (length: $50 \mathrm{~cm} \times$ width: $24 \mathrm{~cm} \times$ height: $30 \mathrm{~cm}$ ). The aquaria had sand as substrate and one shelter per fish. These shelters were made of grey PVC tubes (length: $10 \mathrm{~cm}$, opening diameter: $2 \mathrm{~cm}$ ) with one end closed by an opaque dark plastic film. The PVC tubes were distributed perpendicular to the main axis of the aquaria and parallel to each other, with a distance of $6.5 \mathrm{~cm}$ between them in the high density treatment, and of $13 \mathrm{~cm}$ in the low density treatment. Such densities and nest distances are within the range of those found in the natural population (personal observation). In each replicate, fish were matched for size resulting in a coefficient of variation of the individual's TL in each aquarium of less than 5\%. Five replicates of the high density and 9 of the low density treatment were conducted.

\subsection{Behavioural observations}

Behavioural observations started the day after the individuals were introduced in the treatment aquaria. Each morning focal observations [36] of 20 min were conducted in each aquarium. Observations started $30 \mathrm{~min}$ after the lights went on, from 9:30 to 14:00 approximately. The time of the start of the observations of the different aquaria was randomized. A total of 28 observations per replicate were conducted during the 30 days of the experiment. During focal observations, the behaviours of all the individuals present in the aquarium were registered and subsequently analysed using The Observer software (Noldus Information Technology, Wageningen, The Netherlands). Within agonistic behaviours, charges, bites, chases and flights were treated as events and their frequency was registered; dorsal fin erection and ventral presentation were treated as states and both their frequency and duration were recorded. Ventral presentation, a submissive behaviour, was defined as the individual laying on its flanks immobile or swimming very slowly while presenting its abdomen to another fish. Dorsal presentation, a nearly identical behaviour, has been described for another blenny as inhibiting aggressive behaviour [37]. A social interaction was considered to occur when any behaviour was directed to an individual, irrespective of the reaction of the receiver of the behaviour. The end of the interaction was determined as the absence of behaviour from any of the participants for more than $3 \mathrm{~s}$. Defeats were determined by fleeing behaviour or ventral presentation and the outcome of the agonistic interactions was used to assess social dominance. Individuals were classified as dominant, intermediate or subordinate males according to a simulation statistic procedure that allows the identification of individuals that won or lost more agonistic interactions within their social groups than would have been predicted by chance [38]. If the number of victories was higher than expected by random distribution (one-tailed tests) individuals were considered dominant; individuals with a number of defeats higher than expected were considered subordinate; and individuals whose defeats and victories were not different from random expectations were classified of intermediate status. Only 5 of the 57 individuals tested were classified as intermediate, 2 in the low density treatment and 3 in the high density treatment. The intermediate group was excluded from the statistical analyses where social dominance was used as a grouping factor because the use of such small groups would compromise the power of the analyses. Courtship behaviour was also registered as a state and two types were considered: male-like or female-like courtship displays. Male courtship display consists of jerking the body laterally while protruding the head from the nest. Other courtship behaviours described for the species like zigzag swimming, in which the male leaves the shelter and circles the female, are rare in this population and were not quantified. The female courtship display is characterized by rapid movements of the opercula, fanning the pectoral fins and waving the dorsal and caudal fins while the body is usually vertical with the belly exposed to the male [39]. Courtship displays were only analysed as such if they occurred in a courtship context, namely if one of the participants was in the nest. The context is important because, in this species, female-like courtship behaviour may also be expressed in agonistic context as a submissive behaviour. The position of the individuals in relation to the nest was also registered as a state. Detailed behavioural descriptions for this species can be found in Fishelson [24], Patzner et al. [39] and Uiblein [40].

\subsection{Steroid extraction and quantification}

Plasma samples were extracted for the free, sulphate and glucoronide steroid phases for the subsequent quantification by radio-immunoassay of 11-KT, T and cortisol using the methods described in Canário and Scott [41] and Scott and Canário [42]. Steroid residues were dissolved in $1 \mathrm{ml}$ of $0.1 \mathrm{M}$ phosphate buffer, $\mathrm{pH} \mathrm{7.6,}$ containing gelatine $(1 \mathrm{~g} / \mathrm{L})$, and stored again at $-20{ }^{\circ} \mathrm{C}$ until radioimmunoassay (RIA) was conducted. The three extracted steroid phases were mixed in equal parts and RIAs were carried out to quantify the hormonal concentration in the mix. The antibody for 11-KT was kindly donated by D.E. Kime and its cross-reactivities were described in Kime and Manning [43]. The antibody for T was purchased from Research Diagnostics (RDI-TRK2T2, Concord, USA), and the cross-reactivities provided by the supplier are $16 \%$ for $5 \alpha$-dihydrotestosterone, $1 \%$ for androstenediol, $0.4 \%$ for androstenione, $<0.1 \%$ for androsterone, $<0.1 \%$ for dehydroepiandrosterone, $<0.1 \%$ for progesterone, $0.001 \%$ for estradiol and $0.001 \%$ for cortisol/pregnenolone. For the quantification of cortisol, the antibody supplied by Interchim (20-CR50, Montluçon, France) was used and its cross-reactivities are 5.7\% for 11-desoxycortisol, 3.3\% for corticosterone and less than $0.7 \%$ for cortisone, according to the supplier. The analyses of each hormone were conducted in a single assay per hormone and the intra-assay coefficients of variation were $3.8 \%$ for $11-\mathrm{KT}, 5.9 \%$ for $\mathrm{T}$ and $1.3 \%$ for cortisol.

Because of the small size of our study species, the plasma volume obtained was occasionally lower than optimal for the radioimmunoassay. With lower plasma volumes, an increase in variation of the quantitated androgen levels is expected and a posteriori outlier tests detected, in fact, upper outlier values (exceeding 3rd quartile +1.5 interquartile range) of androgen levels in plasma samples with volumes smaller than $10 \mu \mathrm{l}$. Therefore, plasma volumes lower than $10 \mu \mathrm{l}$ were excluded from the analyses. 


\subsection{General statistical procedures}

The goal of the experiment was to test the effects of social dominance, an individual level variable, and of density, a group (replicate) level variable. Because individuals are nested in replicates, social dominance values within each replicate are not independent of each other. General linear mixed models allow the analysis of these different organizational levels and compose appropriate degrees of freedom, and consequently significance levels, under restricted maximum likelihood estimation. Social dominance and density were introduced as fixed effects and replicates (experimental aquaria) as random effects in a hierarchical linear model of random intercepts. Univariate tests were conducted to test the effect on each dependent variable. For the analysis of SSC, a covariate, total length (TL), was introduced in the model as a fixed effect in order to control the effect of density and dominance on SSC for TL. With the same purpose, eviscerated body weight was introduced as a covariate in the analysis of the weight of gonads. Endocrinological and behavioural variables, the area of the testicular glands and TL were analysed without covariates. Initial TL was also analysed without the random effects of replicates to evaluate a possible association of absolute body size and dominance. The analyses were run on SPSS 17.0 (statistical package for the social sciences) for Windows (Chicago: SPSS Inc.). Significance levels were 0.05 and statistical tests were two-tailed. Both testes and testicular glands were considered to have an elliptical shape for the computation of their areas. The gonadossomatic index (GSI) was calculated as the weight of both testes/eviscerated body weight and the body condition factor (adjKTL) as body weight/ (total length) ${ }^{\mathrm{b}}$, where $\mathrm{b}$ is the slope of the body length (TL)-body weight (W) relationship $(\log \mathrm{W}=\mathrm{a}+\mathrm{blog} \mathrm{TL})$.

Variables that did not meet the assumptions of parametric statistics were either logarithm (log) or, in the case of count data, square root transformed, as it will be mentioned in the Results section. Behavioural variables that showed very low frequencies, like courtship displays, were analysed by simulation statistics using the software ACTUS (Analysis of Contingency Tables Using Simulation [44]). Goodness-of-fit simulation tests were conducted using ADERSSIM software [38].

\subsection{Assessment of mediation and moderation effects}

To assess possible mediation and moderation roles of hormones or body condition on the effect of social dominance on the expression of the reproductive tactics, multiple regression analysis was used $[45,46]$. Social dominance was operationalized as a continuous variable for introduction in the regression model, by using the dominance index proposed by Barlow and Ballin [47]: dominance index $=$ [number of victories / (number of victories + number of defeats)]. The use of this second method to assess social dominance (in addition to the simulation procedure described above) was necessary for using different statistical procedures and is justified by the fact that the two methods are mutually consistent, that is, individuals classified as dominant or subordinate males by the simulation statistics procedure differed significantly in their dominance indexes (average values of dominance index computed for dominant $=0.90$, intermediate $=0.49$ and subordinate $=$ 0.17 individuals; $F 1,54=172.08, \mathrm{p}<0.001$ ).

The mediation effect or indirect effect is the simplest model of path analysis. The mediation is the effect of an independent variable on an outcome variable that is accomplished by a third variable, the mediator. The independent variable $(\mathrm{X})$ determines the mediator (Me) which in turn determines the value of the outcome variable (Y). We first tested the significance of the regression of Me on $\mathrm{X}$. Whenever this effect was not significant the mediation hypothesis was excluded; otherwise the mediation effect was tested by the collapsibility test [45]: $\left(b-b^{\prime}\right) /\left|\rho X M e ~ o b^{\prime}\right|$. In this test, $b$ is the total effect, the unstandardized coefficient of regression of $\mathrm{Y}$ on $\mathrm{X}, \mathrm{b}^{\prime}$ is the direct effect of $\mathrm{Y}$ on $\mathrm{X}$, the unstandardized coefficient of regression of $\mathrm{Y}$ on $\mathrm{X}$ when controlled for Me, $\rho \mathrm{XMe}$ is the correlation coefficient between $\mathrm{X}$ and Me and $\mathrm{ob}^{\prime}$ is the standard error of $\mathrm{b}^{\prime}$. This statistic follows a $\mathrm{t}_{\mathrm{n}-3}$ distribution.

The moderator effect is the effect of the interaction between an independent $(\mathrm{X})$ and a moderator (Mo) variable on an outcome variable $(Y)$. The moderator does not cause $Y$ but it changes the relation between $\mathrm{X}$ and $\mathrm{Y}$, therefore the effect of $\mathrm{X}$ on $\mathrm{Y}$ may be seen as dependent on the value of Mo. The interaction term is usually the product $\mathrm{X} *$ Mo. The effect is tested by a hierarchical multiple regression in which both $\mathrm{X}$ and Mo are introduced in the model in a first step and the interaction term is added in the second step of the analysis. All variables except the outcome are standardized. The moderator effect is accepted if the fit of the data improves with the addition of the interaction term, i.e., if F-change $\neq 0$ [46].

\subsection{Ethical note}

The number of individuals captured and sacrificed was kept to a minimum and biological material collection for complementary studies was maximized. Fish were always anaesthetized before manipulation and recovered from anaesthesia in a small isolation aquarium with abundant aeration. Fish were introduced in the experimental aquaria together with other individuals and were monitored for the first hours.

All animal protocols were performed under a "Group-1" licence from the "Direcção-Geral de Veterinária, Ministério da Agricultura, do Desenvolvimento Rural e das Pescas, Portugal". The experimental procedure followed the ASAB/ABS Guidelines for the Use of Animals in Research and the American Veterinary Medical Association Guidelines on Euthanasia (American Veterinary Medical Association, 2007).

\section{Results}

\subsection{Behavior}

Within the 5 high density replicates, 3 had 1 dominant male and 2 replicates showed 2 dominant males. Within the 9 low density replicates, 7 had 1 dominant individual and in 2 replicates there were 2 dominant individuals. The analysis of frequency of the different social dominance categories (dominant vs intermediate vs subordinate males) in the two density treatments, through simulated contingency tables, did not reveal any difference between treatments in terms of proportion of individuals with different dominance statuses (ACTUS simulation statistic, contingency table of density treatment $\times$ dominance status, chi-square test: $\left.\chi_{2,57}^{2}=1.995 ; \mathrm{p}=0.39\right)$. Dominant males occupied preferentially 1 ( $47 \%$ of the males), 2 (35\% of the males) or 3 (17\% of the males, all in the high density treatment) nests, as tested on the ADERSSIM software by chi-square goodness-of-fit tests in which the number of seconds spent inside the nests was compared to values expected from a uniform distribution of each dominant male by the different nests.

The behaviour of dominant males was similar to the behaviour of nest-holder males in that they occupied nests for a longer period of time and participated in more agonistic interactions than subordinate males. Together these two variables were interpreted, and will be referred to, as nest defence. Furthermore, density and dominance status interacted to influence both the participation in agonistic interactions and the time inside the nest, the latter presenting only a marginally non-significant interaction effect. The positive effect of social dominance on time spent inside the nest was stronger in the low density treatment (Table 1, estimated marginal means of time inside the nest at low density: dominant males $=3 \mathrm{~h} 32 \mathrm{~min} \pm 24 \mathrm{~min}$ and subordinate males $=38 \mathrm{~min} \pm 23 \mathrm{~min}$; at high density: dominant males $=2 \mathrm{~h}$ $23 \mathrm{~min} \pm 31 \mathrm{~min}$ and subordinate males $=36 \mathrm{~min} \pm 26 \mathrm{~min}$ ) but the effect on the number of agonistic interactions was stronger in the high 
Table 1

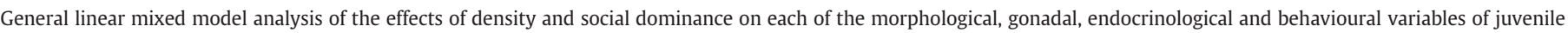

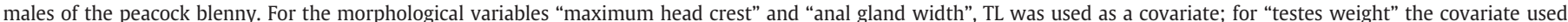

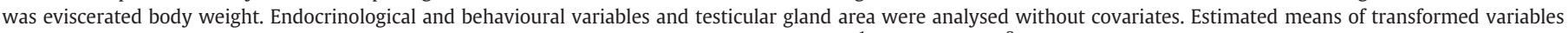
are reconverted to the original scale. Marginally non-significant F-test values are represented by ${ }^{1}$ if $p=0.06$ and ${ }^{2}$ if $p=0.09$.

\begin{tabular}{|c|c|c|c|c|c|c|}
\hline & & \multirow[t]{2}{*}{ Density } & \multirow[t]{2}{*}{ Dominance status } & \multicolumn{2}{|c|}{$\begin{array}{l}\text { Estimated marginal means } X \pm S E \text { (transformed } \\
\text { variables reconverted: } X-S E / X / X+S E \text { ) }\end{array}$} & \multirow[t]{2}{*}{ Density $\times$ dominance status } \\
\hline & & & & Dominant males & Subordinate males & \\
\hline \multirow{4}{*}{$\begin{array}{l}\text { Pre-experiment } \\
\text { values }\end{array}$} & TL (across replicates) & & $\mathrm{F}_{1,50}=1.189$ & & & \\
\hline & TL (within replicates) & $\mathrm{F}_{1,11.932}=0.035$ & $F_{1,36.004}=21.160^{* * *}$ & $6.61 \pm 0.27 \mathrm{~cm}$ & $6.33 \pm 0.27 \mathrm{~cm}$ & $F_{1,36.004}=0.658$ \\
\hline & Maximum head height & $\mathrm{F}_{1,11.152}=0.583$ & $\mathrm{~F}_{1,40.896}=2.990$ & $1.06 \pm 0.01 \mathrm{~cm}$ & $1.04 \pm 0.01 \mathrm{~cm}$ & $F_{1,37.506}=0.283$ \\
\hline & Anal gland width & $\mathrm{F}_{1,5.407}=2.701$ & $F_{1,24.818}=0.579$ & $1.23 \pm 0.06 \mathrm{~mm}$ & $1.18 \pm 0.05 \mathrm{~mm}$ & $F_{1,22.945}=2.849$ \\
\hline \multirow{7}{*}{$\begin{array}{l}\text { Post-experiment } \\
\text { values }\end{array}$} & Maximum head height & $F_{1,10.863}=0.358$ & $\mathrm{~F}_{1,41.755}=13.559^{* *}$ & $1.25 \pm 0.02 \mathrm{~cm}$ & $1.17 \pm 0.02 \mathrm{~cm}$ & $F_{1,35.677}=0.100$ \\
\hline & Anal gland width & $F_{1,11.766}=3.374^{2}$ & $\mathrm{~F}_{1,43.737}=3.874^{1}$ & $1.29 \pm 0.08 \mathrm{~mm}$ & $1.14 \pm 0.07 \mathrm{~mm}$ & $F_{1,37.689}=0.001$ \\
\hline & Testicular gland area & $\mathrm{F}_{1,11.229}=0.777$ & $\mathrm{~F}_{1,36.247}=6.167^{*}$ & $1.93 \pm 0.30 \mathrm{~mm}^{2}$ & $1.35 \pm 0.27 \mathrm{~mm}^{2}$ & $F_{1,36.247}=1.687$ \\
\hline & Testes weight & $\mathrm{F}_{1,11.543}=0.681$ & $\mathrm{~F}_{1,43.245}=0.024$ & $0.005 \pm 0.003 \mathrm{~g}$ & $0.005 \pm 0.003 \mathrm{~g}$ & $F_{1,36.369}=1.548$ \\
\hline & 11-KT (log) & $\mathrm{F}_{1,4.397}=0.114$ & $\mathrm{~F}_{1,18.052}=6.832^{*}$ & $2.00 / 2.38 / 2.82 \mathrm{ng} \mathrm{ml}^{-1}$ & $1.17 / 1.37 / 1.61 \mathrm{ng} \mathrm{ml}^{-1}$ & $\mathrm{~F}_{1,18.052}=1.381$ \\
\hline & $\mathrm{T}(\log )$ & $F_{1,5.516}=0.152$ & $\mathrm{~F}_{1,18.057}=7.938^{*}$ & $11.25 / 14.06 / 17.58 \mathrm{ng} \mathrm{ml}^{-1}$ & $5.58 / 6.90 / 8.55 \mathrm{ng} \mathrm{ml}^{-1}$ & $\mathrm{~F}_{1,18.057}=0.970$ \\
\hline & Cortisol & $F_{1,8.651}=0.152$ & $F_{1,18.027}=3.166$ & $8.45 / 12.05 / 17.18 \mathrm{ng} \mathrm{ml}^{-1}$ & $4.98 / 7.10 / 10.12 \mathrm{ng} \mathrm{ml}^{-1}$ & $\mathrm{~F}_{1,18.057}=0.268$ \\
\hline \multirow[t]{2}{*}{ Experiment values } & $\begin{array}{l}\text { No. of agonistic interactions } \\
\text { (square root) }\end{array}$ & $\mathrm{F}_{1,11.532}=0.030$ & $\mathrm{~F}_{1,36.125}=36.583^{* * *}$ & $351 / 399 / 450$ & $200 / 235 / 272$ & $\mathrm{~F}_{1,36.125}=10.709^{* *}$ \\
\hline & Time in nest & $\mathrm{F}_{1,10.721}=1.174$ & $\mathrm{~F}_{1,36.048}=66.612^{* * *}$ & $2 \mathrm{~h} 57 \mathrm{~min} \pm 20 \mathrm{~min}$ & $37 \min \pm 17 \min$ & $F_{1,36.048}=3.756^{1}$ \\
\hline
\end{tabular}

${ }^{*}$ Indicates significant F-test values at the significance level of 0.05 .

** Indicates significant F-test values at the significance level of 0.01 .

*** Indicates significant F-test values at the significance level of 0.001 .

density treatment (Table 1, estimated marginal values of agonistic interactions, transformed data reconverted to original scale, at low density: dominant males $\mathrm{X}-\mathrm{SE} / \mathrm{X} / \mathrm{X}+\mathrm{SE}=303 / 358 / 417$ and subordinate males 235 / 282 /333; at high density: dominant males 364 / 443/ 530 and subordinate males 145/192/246). The frequency of femalelike courtship, that parasitic males usually display when approaching the nests, was however very low and did not differ between dominant and subordinate males (ACTUS simulation statistic, chi-square test: $\chi^{2} 21,52=0.85 ; p=0.38$ ). The effect of density on the behaviour of the immature males was not significant for any of the variables analysed (Table 1).

\subsection{Morphology}

Within each replicate, the fish that became dominant were significantly larger (TL) at the beginning of the experiment than those that became subordinate. However, there was no overall difference between the initial TL of dominant and subordinate males across replicates. There were no significant differences between individuals that would later become dominant or subordinate in the development of SSC (head crest or anal gland relative size) at the beginning of the experiment (Table 1). At the end of the experiment, and controlling for body size, dominant males showed larger head crest and anal glands than subordinate males, but the differences in anal gland size were only marginally non-significant $(p=0.055)$. However, it should be mentioned that at the end of the experiment there were no individuals with SSC fully developed, as found in the reproducing nest-holders in nature. Dominant males had larger testicular glands than subordinate males but the weight of testes controlled for eviscerated body weight did not differ between dominant and subordinate males (Table 1 ). All but four individuals were still sexually immature (with low GSI $=0.18 \pm 0.042$ ) at the end of the experiment. These four fish had well-developed testes typical of parasitic males and were all subordinate males (two in the low density and two in the high density treatment). In summary, dominant and subordinate fish differed in all the morphological traits that distinguish nest-holder from parasitic males but not in the relative size of testes. No effect of density was detected for any of the measured variables but a marginally non-significant $(p=0.09)$ trend for males of the low density treatment to exhibit larger anal glands than those of the high density treatment was detected (Table 1 ).

\subsection{Hormones}

Dominant individuals exhibited higher circulating levels of 11-KT and $\mathrm{T}$, but not of cortisol, than subordinates and there was no effect of density on circulating levels of steroids (Table 1 ). Cortisol was negatively correlated with GSI $(r=-0.39, \mathrm{p}=0.03, \mathrm{n}=30$, GSI was $\log$ transformed).

\subsection{Mediator and mediation effects}

Possible mediation by steroids or body condition of the effect of social dominance on the expression of the different traits that characterize each tactic was tested. The dominance index could predict androgen levels, the potential mediators $\left(11-\mathrm{KT}=1.19+1.51 \mathrm{Di}, \mathrm{r}^{2}=\right.$ 0.26, $\mathrm{p}<0.01, \mathrm{n}=30 ; \mathrm{T}=4.64+14.20 \mathrm{Di}, \mathrm{r}^{2}=0.27, \mathrm{p}<0.01, \mathrm{n}=30$ ). The results of the collapsibility test (Table 2 ) support the hypothesis that the effect of social dominance on the development of SSC and on nest defence behaviour are mediated by the levels of circulating 11-KT and T, respectively. Where the results supported a mediation effect through androgen levels, the role of the testicular gland as determinant of these levels was estimated by a new mediation test. An effect of the area of the testicular gland on the development of the head crest, mediated by circulating levels of 11-KT, and on nest defence behaviour, mediated by circulating levels of $\mathrm{T}$, was detected (Table 2). Neither levels of cortisol in plasma (cortisol $=9.22+$ 10.52Di, $\mathrm{r}^{2}=0.09, \mathrm{p}=0.11, \mathrm{n}=30$ ) nor body condition at the end of the experiment $\left(\operatorname{adjK}_{\mathrm{TL}}=0.01+0.00 \mathrm{Di}, \mathrm{r}^{2}=0.04, \mathrm{p}=0.12, \mathrm{n}=57\right)$ was associated with social dominance, therefore a possible mediation effect is excluded a priori.

The data supported a moderation role of initial body condition, i.e., the effect of dominance on SSC was dependent on body condition at the start of the experiment (Table 3). For individuals with above average initial body condition, social dominance predicted the expression of the head crest (maximum head height $/ \mathrm{TL}=0.17+0.02 \mathrm{Di}, \mathrm{r}^{2}=$ $0.48, \mathrm{p}<0.01, \mathrm{n}=21$ ) and of the anal gland (anal gland width $/ \mathrm{TL}=$ $0.015+0.08 \mathrm{Di}, \mathrm{r}^{2}=0.31, \mathrm{p}<0.01, \mathrm{n}=21$ ) but for males with initial body condition below the average, social dominance was not associated with head crest (maximum head height $/ \mathrm{TL}=0.16+0.01 \mathrm{Di}$, $\mathrm{r}^{2}=0.05, \mathrm{p}=0.20, \mathrm{n}=35$ ) or anal gland (anal gland width $/ \mathrm{TL}=$ $0.015+0.02 \mathrm{Di}, \mathrm{r}^{2}=0.04, \mathrm{p}=0.25, \mathrm{n}=36$ ) development (Fig. 1A, B). Contrarily, initial body condition did not moderate the effect of dominance on GSI, development of the testicular glands, nest defence 
Table 2

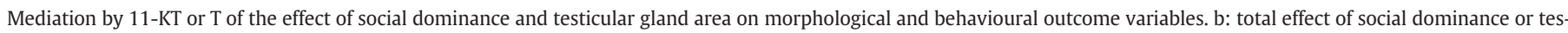

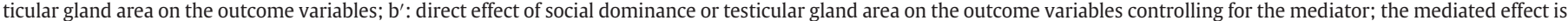
tested by a collapsibility test. Head crest relative size $=$ maximum head height $/$ total length, anal gland relative size $=$ anal gland maximum width $/$ total length. $\mathrm{N}=30$.

\begin{tabular}{|c|c|c|c|c|c|c|}
\hline \multicolumn{3}{|l|}{ Mediator (Me) } & \multicolumn{2}{|l|}{$11-\mathrm{KT}$} & \multicolumn{2}{|l|}{$\mathrm{T}$} \\
\hline $\begin{array}{l}\text { Independent variables } \\
(\mathrm{X})\end{array}$ & $\begin{array}{l}\text { Outcome variables } \\
\text { (Y) }\end{array}$ & $\begin{array}{l}\text { Total effect } \\
\text { (b) }\end{array}$ & $\begin{array}{l}\text { Direct effect } \\
\left(b^{\prime}\right)\end{array}$ & $\begin{array}{l}\text { Mediated effect } \\
\left(b-b^{\prime}\right) /\left|\rho X M e ~ o b^{\prime}\right|\end{array}$ & Direct effect $\left(b^{\prime}\right)$ & $\begin{array}{l}\text { Mediated effect } \\
\left(b-b^{\prime}\right) /\left|\rho X M e ~ o b^{\prime}\right|\end{array}$ \\
\hline \multirow[t]{4}{*}{ Social dominance } & Head crest relative size & $0.020^{* *}$ & 0.011 & $21.941^{* * *}$ & 0.019 & 0.259 \\
\hline & Anal gland relative size & $0.059^{* *}$ & 0.056 & $2.258^{*}$ & 0.080 & -1.625 \\
\hline & No. of agonistic interactions & $301.699^{* *}$ & 229.052 & 1.364 & 198.816 & $1.966^{*}$ \\
\hline & Time in nest & $238.358^{* *}$ & 246.628 & -0.391 & 201.249 & $1.822^{*}$ \\
\hline \multirow[t]{4}{*}{ Testicular gland } & Head crest relative size & $0.007^{* *}$ & 0.005 & $3.279^{* * *}$ & & \\
\hline & Anal gland relative size & $0.028^{* *}$ & 0.026 & 1.093 & & \\
\hline & Anal gland relative size & 46.616 & & & 39.842 & $3.245^{* * *}$ \\
\hline & Time in nest & 28.032 & & & 24.088 & $3.754^{* * *}$ \\
\hline
\end{tabular}

* Indicates significant mediation effects, $\mathrm{p}<0.05$.

** Indicates significant mediation effects, $\mathrm{p}<0.01$.

*** Indicates significant mediation effects, $\mathrm{p}<0.001$.

behaviour or on levels of 11-KT (Table 3). Cortisol did not influence the effect of dominance on reproductive tactic expression but the data supported a moderation effect of cortisol on the expression of agonistic behaviour. Dominant males with higher levels of cortisol participated in more agonistic interactions than those with lower levels, conversely subordinate males with higher levels of cortisol showed less agonistic behaviours than those with lower levels (Table 3; Fig. 1C).

\section{Discussion}

Social dominance influenced the expression of the first reproductive phenotype of the peacock blenny. A higher social status promoted not only nest defence behaviour but also the development of testicular glands, an increase in androgen levels and the growth of SSC, traits that characterize the nest-holder tactic (the bourgeois phenotype). Therefore social dominance can influence the expression of ART, even when these involve slower developing traits like SSC.

The emerging social hierarchy established within replicates predicted the development towards the different ART. The social status was not predicted by absolute body size but the small differences in the initial relative body size (within social groups) could predict the dominance status achieved by the end of the experiment. The expression of reproductive tactics has been shown to depend on body size in different life stages of some invertebrate species (e.g. $[19,48,49])$ and on social dominance in the case of the cichlid N. pulcher. Body size difference is an important determinant of social dominance in fish $[50,51]$ and, as in S. pavo, in N. pulcher social dominance is dependent on relative body size [2]. Therefore, relative body size and associated

\section{Table 3}

Moderation tests of circulating cortisol levels and body condition $\left(\operatorname{adj}_{\mathrm{TL}}\right)$ on the effect of social dominance (dominance index) on the outcome variables. Head crest relative size $=$ maximum head height $/$ total length, anal gland relative size $=$ anal gland maximum width/total length. $\mathrm{r}^{2} \mathrm{adj}=$ adjusted coefficient of determination of the regression of each of the outcome variable on the dominance index and each of the moderators; $\mathrm{r}^{2} \mathrm{adj}_{\mathrm{int}}$ includes additionally the interaction term (dominance index $\times$ moderator) as an independent variable. Significant $\mathrm{F}_{\text {change }}$ is represented by ${ }^{*}$ at 0.05 and by ${ }^{* *}$ at the 0.01 significance level.

\begin{tabular}{|c|c|c|c|c|c|c|}
\hline \multirow{2}{*}{$\begin{array}{l}\text { Moderator (Mo) } \\
\text { Outcome variables }(\mathrm{Y})\end{array}$} & \multicolumn{3}{|c|}{ Cortisol } & \multicolumn{3}{|c|}{ Body condition $\left(\operatorname{adjK}_{\mathrm{TL}}\right)$} \\
\hline & $\mathrm{r}^{2} \mathrm{adj}$ & $\mathrm{r}^{2} \mathrm{adj}_{\mathrm{int}}$ & $\overline{F_{\text {change }}}$ & $\mathrm{r}^{2} \mathrm{adj}$ & $\mathrm{r}^{2} \mathrm{adj}_{\text {int }}$ & $\mathrm{F}_{\text {change }}$ \\
\hline Head crest relative size & 0.252 & 0.223 & 0.007 & 0.425 & 0.495 & $8.314^{* *}$ \\
\hline Anal gland relative size & 0.226 & 0.198 & 0.072 & 0.163 & 0.267 & $8.639^{* *}$ \\
\hline GSI (log) & 0.124 & 0.123 & 0.963 & 0.099 & 0.083 & 0.094 \\
\hline Testicular gland area & 0.106 & 0.075 & 0.097 & 0.102 & 0.087 & 0.086 \\
\hline No. of agonistic interactions & 0.286 & 0.388 & $5.471^{*}$ & 0.164 & 0.164 & 0.984 \\
\hline Time in nest & 0.595 & 0.580 & 0.004 & 0.484 & 0.478 & 0.423 \\
\hline $11-\mathrm{KT}$ & & & & 0.412 & 0.450 & 2.864 \\
\hline
\end{tabular}

dominance status may constitute an important social cue for ART expression in fish in general but also in other taxa.

In the African tilapia, A. burtoni, social dominance stimulates growth of GnRH producing neurons in the POA and this promotes the production of gonadotropins, which in turn trigger sexual maturation, androgen production and consequently sexual coloration [52,53]. However, in the peacock blenny, as in most typical ART patterns, sexual maturation and sexual traits, like SSC, are dissociated. Parasitic males, which have no SSC, are not only sexually mature but are in fact those who exhibit larger gonads. This dissociation is visible in our data. By the end of this experiment most individuals had, surprisingly, only vestigial gonads, in spite of the fact that dominant males significantly increased the development of SSC in comparison with subordinates. Such dissociation between the growth of SSC and testes development can hypothetically be achieved by the testicular glands. These glands are, in this species, the major producers of androgens in the testes and androgen concentration measured in testicular glands closely correlates with circulating levels of androgens but not with the levels of androgens in the remaining testicular tissue [27]. Therefore steroidogenic activity in these glands seems to be independent from steroidogenic activity in the testes. In accordance, in the end of the experiment dominant males had more developed testicular glands than subordinate males and higher circulating levels of $\mathrm{T}$ and 11-KT. Furthermore, the data supported a mediation effect of $11-\mathrm{KT}$ in the development of the head crest in response to both social dominance and testicular gland size. This in agreement with previous experiments showing that androgen administration, in particular of 11-KT, stimulates the development of male SSC in parasitic males of S. pavo $[32,34]$. Social dominance also promoted nest defence behaviour and again the data suggests a role for androgens, in this case T, in mediating this effect. This result should be interpreted with some caution as, despite theory predicting a bidirectional relationship between androgens and aggressive behaviour [9,55], previous studies conducted on this species show no effect of 11-KT, T or estradiol on territorial and/or nest defence behaviour in parasitic males [32,34]. Nevertheless, the results obtained in this study for androgens are in agreement with male morphological characters being mostly dependent on 11-KT, with this hormone having a minor effect in the modulation of sexual behaviour in fish [56]. In conclusion, the results suggest that a higher dominance status promoted the development of the testicular gland and higher plasma levels of androgens that, in turn, facilitated the development of bourgeois male traits.

One question that remains to be answered is the different mechanisms through which testes develop with or without a testicular gland. If a mechanism similar to that of $A$. burtoni is present in S. pavo, in which social dominance stimulates the release of gonadotropins, the development of testes with testicular glands could be achieved in two ways: 1 ) by a change in the expression of gonadotropin receptors in the testes vs the testicular gland; 2 ) by a differential 
A

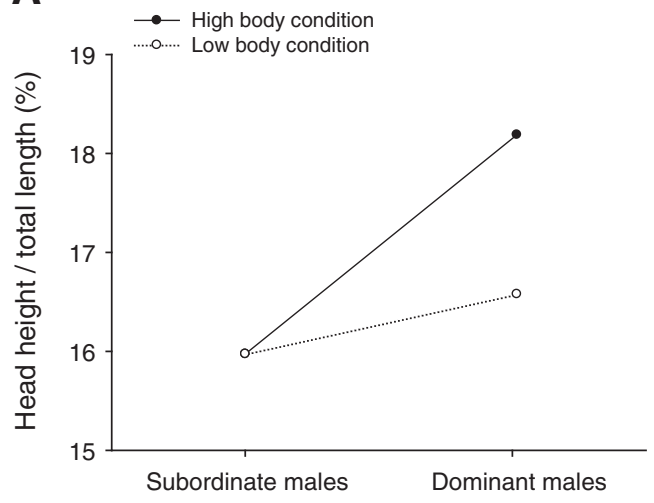

B

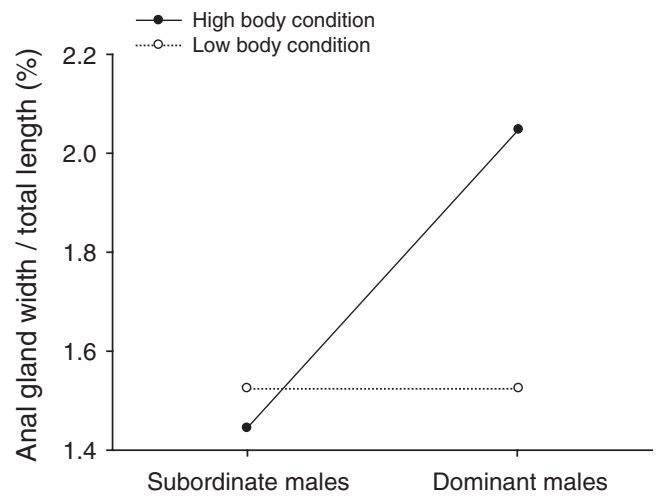

C

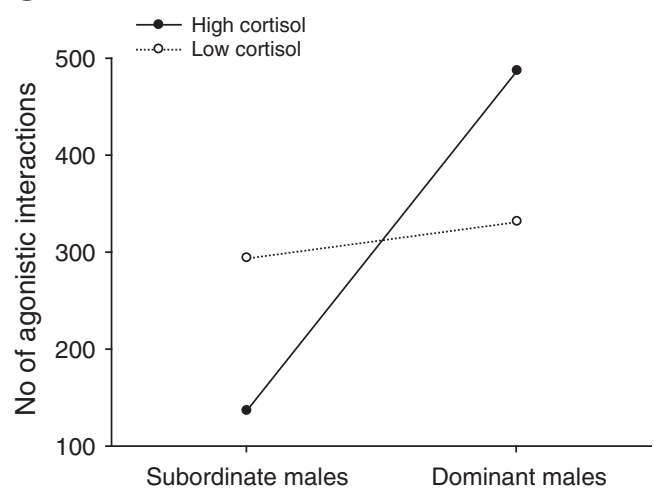

Fig. 1. Moderation by body condition on the effect of social dominance on the expression of secondary sexual characters, namely on: A) relative size of head crest and B) relative size of anal gland. C) Moderation by circulating levels of cortisol on the effect of social dominance on the number of agonistic interaction. Dominant and subordinate males are defined here as average dominance index $+1 \mathrm{SE}$ and $-1 \mathrm{SE}$, respectively. The same is true for the categorization of body condition and cortisol values.

production and release of the two gonadotropins by the pituitary gland, as for example, a higher LH/FSH ratio, given the known steroidogenic effect of LH [54]. Both mechanisms could promote the development of testicular glands and their steroidogenic function, independent of gonadal development, not only in S. pavo but also in other species possessing similar structures.

However, social dominance was not a sufficient condition for the development of the bourgeois tactic at this life stage. A low body condition prevented the effects of social dominance on the development of SSC. Body condition did not moderate the effects of social dominance in the development of the testicular gland or on 11-KT. Therefore, low body condition seems to limit the growth of SSC and while dominant males in good condition were able to grow larger SSC, those in low condition, even if dominant, were unable to develop their SSC.

Social dominance did not determine circulating levels of cortisol and accordingly a mediation role of this hormone on the effect of social dominance on tactic expression was not supported by the data. Equally, no support was found for a moderation role of cortisol on the expression of the reproductive tactics but, interestingly, the data did agree with a moderation role of cortisol in the expression of agonistic behaviour. Although social dominance in this species does not determine cortisol levels both of these factors interact, so that dominant males with high cortisol levels participated in more agonistic interactions whereas subordinate males with high cortisol levels avoided such interactions. However, once again, due to the reciprocal nature of the relationship between hormones and behaviour, interpretation of causality should be cautious. Moreover, circulating levels of cortisol were inversely correlated with GSI. The negative association between cortisol and GSI agrees with previous studies in pubertal male common carp, Cyprinus carpio, showing that cortisol retards gonadal development $[57,58]$. Therefore, cortisol may play an inhibitory role in testicular development also in this species, a hypothesis that deserves further attention.

Density is another characteristic of the social environment known to affect the expression of alternative tactics in other species, namely invertebrates $[20,59]$. Low density may signal weak male-male competition and thus constitute an optimal cue for the development of the bourgeois tactic, since the success of this tactic is dependent on resource defence. However, in our experiment density did not influence the development of juvenile males. The fact that relative body size influenced tactic expression shows that juvenile males were sensitive to cues of the social environment. Thus, the absence of an effect of density is better explained by a low importance of this variable in determining tactic choice. Within each social group, dominant juvenile males defended 1 to 3 nests more intensively and chased other males away from those nests. In the field, nest sites are aggregated having a short distance between them (similar to the distances used in the present experiment). It is likely that such nest-site proximity may render social dominance a cue for tactic choice that is stronger than density, because it allows dominant males to control much of the resources irrespectively of the local male-to-nest ratio, which is dependent on density.

The dissociation observed in this study between male morphology and GSI permits that males that do not exhibit SSC may still mature and reproduce. In other words, it allows for the existence of the female mimicking tactic. Furthermore, it may on its own determine the different morphotypes and ontogenetic pathways followed by males of this population. The results suggest that young dominant males will express the nest-holder tactic directly in their first breeding season. The development of the testicular gland and associated increase in androgen levels seem to be the key for translating social dominance cues into phenotypic changes towards the nest-holder phenotype. Contrarily, subordinate males will restrict the development of the testicular gland and of SSC and may either reproduce as parasitic males or postpone reproduction according to the onset of sexual maturation, which is independent of social dominance. Parasitic and immature males will constitute distinct ontogenetic pathways but both will express the bourgeois tactic in the next breeding season. This switch to a nest-holder phenotype deserves further attention. In the second breeding season, the same cues may determine the beginning of the development of the nest-holder phenotype in these two pathways: as these males grow, their relative body size in the population will increase and their social status will rise, therefore allowing the development of the nest-holder morphotype. However, all males express the bourgeois tactic in their second breeding season therefore alternative hypotheses, as the existence of a size or age limit from which males will obligatorily initiate the expression of SSC, should be considered. 
A translation of the results obtained to field conditions suggests that smaller males in the presence of nest-holders, which are larger and therefore more dominant, will inhibit the development of the testicular gland and of SSC. In this way, subordinate males may maintain their female-like morphology and reproduce as parasitic males. This might explain why the frequency of parasitic males is higher in populations with a shortage and aggregation of nest sites [60], as these conditions are likely to increase the frequency of subordinate juveniles. 11-KT, most likely secreted by the testicular glands, seems to be responsible for the conversion of the dominance status to the expression of SSC but exactly which neuroendocrine mechanisms promote the development of testicular glands remains a crucial question. Further research should investigate the effect of social dominance on possible differential production of gonadotropins and their steroidogenic effect on the testicular glands. Equally, the possible influence of circulating cortisol levels on sexual maturation deserves further investigation.

In conclusion, our study suggests that social dominance, associated with a good body condition, is a key factor promoting the development of the bourgeois tactic in juvenile males of this species and that this is mediated by androgens.

\section{Acknowledgements}

The authors would like to thank Tânia Oliveira for running the RIAS, Albert Ros for helping in field work during the project and the Ria Formosa Nature Park for providing logistic support and allowing the study to be conducted in the nature reserve area. We would also like to thank the anonymous reviewers of the earlier versions of this work for important contributions to the improvement of the manuscript. This study was funded by the research grants POCTI/BSE/38395/2001 and PTDC/MAR/71351/2006 and the R\&D Units Plurianual Program (R\&D unit 331/2001) from the Portuguese Foundation for Science and Technology (FCT). During the course of this project T. Fagundes was being supported by an FCT fellowship (SFRH/BD/6502/2001).

\section{References}

[1] Shuster SM, Wade MJ. Mating systems and strategies. Princeton, NJ: Princeton University Press; 2003.

[2] Fitzpatrick JL, Desjardins JK, Milligan N, Stiver KA, Montgomerie R, Balshine S. Female-mediated causes and consequences of status change in a social fish. Proc Biol Sci 2008;275:929-36.

[3] Fernald RD. Social regulation of reproduction: what changes and why? Horm Brain Behav 2009;1:683-91.

[4] Taborsky M. Bourgeois and parasitic tactics: do we need collective, functional terms for alternative reproductive behaviours? Behav Ecol Sociobiol 1997;41: 361-2.

[5] Bass AH. Sounds from the intertidal zone: vocalizing fish. Bioscience 1990;40: 249-58.

[6] Taborsky M. Sneakers, satellites and helpers: parasitic and cooperative behavior in fish reproduction. In: Slater PJB, Rosenblatt JS, Snowdon CT, Milinski M, editors. Advances in the study of behavior. San Diego: Academic Press; 1994. p. 1-100.

[7] Borg B. Androgens in teleost fishes. Comp Biochem Physiol 1994;109C:219-45.

[8] Gonçalves D, Oliveira RF. Hormones and sexual behavior of teleost fishes. In: Norris D, Lopez KH, editors. Hormones and reproduction of vertebrates. Academic Press; 2010. p. 119-47.

[9] Oliveira RF. Social modulation of androgens in vertebrates: mechanisms and function. In: Slater PJB, Rosenblatt JS, Snowdon CT, Roper TJ, editors. Advances in the study of behavior. New York: Academic Press; 2004. p. 165-239.

[10] Hirschenhauser K, Oliveira RF. Social modulation of androgens in male vertebrates: meta-analyses of the challenge hypothesis. Anim Behav 2006;71:265-77.

[11] Baron RM, Kenny DA. The moderator-mediator variable distinction in social psychological research: conceptual, strategic, and statistical considerations. J Pers Soc Psychol 1986;51:1173-82.

[12] Knapp R, Hews DK, Thompson CW, Ray LE, Moore MC. Environmental and endocrine correlates of tactic switching by nonterritorial male tree lizards (Urosaurus ornatus). Horm Behav 2003;43:83-92.

[13] Leary CJ, Garcia AM, Knapp R. Elevated corticosterone levels elicit non-calling mating tactics in male toads independently of changes in circulating androgens. Horm Behav 2006;49:425-32.

[14] Rodgers EW, Earley RL, Grober M. Social status determines social phenotype in the bi-directional sex changing goby Lythrypnus dalli. J Fish Biol 2007;70:1660-8.
[15] Ejike C, Schreck CB. Stress and social hierarchy rank in coho salmon. Trans Am Fish Soc 1980;109:423-6.

[16] Winberg S, Lepage O. Elevation of brain 5-HT activity, POMC expression, and plasma cortisol in socially subordinate rainbow trout. Am J Physiol 1998;274:R645-54.

[17] Consten LD, Keuning ED, Terlou M, Lambert JGD, Goos HJT. Cortisol effects on the testicular androgen synthesizing capacity in common carp, Cyprinus carpio. Fish Physiol Biochem 2002;25:91-8.

[18] Knapp R. Endocrine mediation of vertebrate male alternative reproductive tactics: the next generation of studies. Integr Comp Biol 2004;43:658-68.

[19] Tomkins JL. Environmental and genetic determinants of the male forceps length dimorphism in the European earwig Forficula auricularia L. Behav Ecol Sociobiol 1999;47:1-8.

[20] Radwan J, Unrug J, Tomkins JL. Status-dependence and morphological trade-offs in the expression of a sexually selected character in the mite, Sancassania berlesei. J Environ Biol 2002;15:744-52.

[21] Immler S, Mazzoldi C, Rasotto MB. From sneaker to parental male: change of reproductive traits in the black goby, Gobius niger (Teleostei, Gobiidae). J Exp Zool A Comp Exp Biol 2004;301:177-85.

[22] Almada VC, Gonçalves EJ, Oliveira RF, Santos AJ. Courting females: ecological constraints affect sex-roles in a natural population of the blenniid fish Salaria pavo. Anim Behav 1995;49:1125-7.

[23] Gonçalves EJ, Almada VC, Oliveira RF, Santos AJ. Female mimicry as a mating tactic in males of the blenniid fish Salaria pavo. J Mar Biol Assoc U K 1996;76:529-38.

[24] Fishelson L. Observations on littoral fishes of Israel I. Behaviour of Blennius pavo Risso (Teleostei, Blenniidae). Isr J Zool 1963;12:67-91.

[25] Papaconstantinou CA. Secondary sex characters of blennioid fishes (Pisces: Blenniidae). Thalassographica 1979;3:57-75.

[26] Patzner RA, Seiwald M. The reproduction of Blennius pavo Risso (Teleostei, Blenniidae). VII. Secondary sexual organs and accessory glands of the testis during the reproductive cycle. V Congr Europ Ichthyol Stockholm 1985:293-8.

[27] Oliveira RF, Canário AV, Grober MS. Male sexual polymorphism, alternative reproductive tactics, and androgens in combtooth blennies (Pisces: Blenniidae). Horm Behav 2001;40:266-75.

[28] Gonçalves D, Teles M, Alpedrinha J, Oliveira RF. Brain and gonadal aromatase activity and steroid hormone levels in female and polymorphic males of the peacock blenny Salaria pavo. Horm Behav 2008;54:717-25.

[29] Gonçalves D, Matos R, Fagundes T, Oliveira RF. Bourgeois males of the peacock blenny, Salaria pavo, discriminate female mimics from females? Ethology 2005;111:559-72.

[30] Reinboth R, Becker B. In vitro-metabolization of $\left[{ }^{14} \mathrm{C}\right]$ testosterone by spermatogenic tissue and the accessory gland of Blennius pavo (Blenniiformes, Teleostei). Gen Comp Endocrinol 1986;5:11-6.

[31] Oliveira RF, Gonçalves EJ, Santos RS. Gonadal investment of young males in two blenniid fishes with alternative mating tactics. J Fish Biol 2001:59:459-62.

[32] Oliveira RF, Carneiro LA, Gonçalves DM, Canário AV, Grober MS. 11-Ketotestosterone inhibits the alternative mating tactic in sneaker males of the peacock blenny, Salaria pavo. Brain Behav Evol 2001;58:28-37.

[33] Carneiro L, Oliveira R, Canário AVM, Grober M. The effect of arginine vasotocin on courtship behaviour in a blenniid fish with alternative reproductive tactics. Fish Physiol Biochem 2003;28:241-3.

[34] Gonçalves D, Alpedrinha J, Teles M, Oliveira RF. Endocrine control of sexual behavior in sneaker males of the peacock blenny Salaria pavo: effects of castration, aromatase inhibition, testosterone and estradiol. Horm Behav 2007;51:534-41.

[35] Gonçalves D, Oliveira RF. Time spent close to a sexual partner as a measure of female mate preference in a sex-role-reversed population of the blenny Salaria pavo (Risso) (Pisces: Blenniidae). Acta Ethologica 2003;6:1-5.

[36] Martin P, Bateson P. Measuring behaviour: an introductory guide. Cambridge: Cambridge University Press; 1993.

[37] Santos RS, Barreiros JP. The ethogram of Parablennius sanguinolentus parvicornis (Valenciennes in Cuvier \& Valenciennes, 1836) (Pisces: Blenniidae) from the Azores. Arquipélago - Sér Ciênc Nat 1993;11A:73-90.

[38] Almada VC, Oliveira RF. Sobre o uso de estatística de simulação em estudos de comportamento. Análise Psicológica 1997;15:97-109.

[39] Patzner RA, Seiwald M, Adlgasser M, Kaurin G. The reproduction of Blennius pavo (Teleostei, Blenniidae) V. Reproductive behavior in natural environment. Zool Anz 1986;216:338-50.

[40] Uiblein F. Zur ethologie des pfauenschleimfisches Blennius (=Salaria) pavo. Nova Thalassia 1989;10:5-88.

[41] Canário AVM, Scott AP. Synthesis of 20a-hydroxylated steroids by ovaries of the dab (Limanda limanda). Gen Comp Endocrinol 1989;76:147-58.

[42] Scott AP, Canário AVM. 17a,20ß-Dihydroxy-4-pregnen-3-one 20-sulphate: a major new metabolite of the teleost oocyte maturation-inducing steroid. Gen Comp Endocrinol 1992;85:91-100.

[43] Kime DE, Manning NJ. Seasonal patterns of free and conjugated androgens in the brown trout Salmo trutta. Gen Comp Endocrinol 1982;48:222-31.

[44] Eastabrook CB, Eastabrook GF. ACTUS: a solution to the problem of analysing sparse contingency tables. Hist Methods 1989;22:5-8.

[45] MacKinnon DP, Lockwood CM, Hoffman JM, West SG, Sheets V. A comparison of methods to test mediation and other intervening variable effects. Psychol Methods 2002;7:83-104.

[46] Frazier PA, Tix AP, Barron KE. Testing moderator and mediator effects in counseling psychology research. J Couns Psychol 2004;51:115-34.

[47] Barlow GW, Ballin PJ. Predicting and assessing dominance from size and coloration in the polychromatic Midas cichlid. Anim Behav 1976;24:793-813.

[48] Emlen DJ. Alternative reproductive tactics and male-dimorphism in the horned beetle Onthophagus acuminatus (Coleoptera: Scarabaeidae). Behav Ecol Sociobiol 1997;41:335-41. 
[49] Emlen DJ, Nijhout HF. Hormonal control of male horn length dimorphism in Onthophagus taurus (Coleoptera: Scarabaeidae): a second critical period of sensitivity to juvenile hormone. J Insect Physiol 2001;47:1045-54.

[50] Whiteman EA, Cote IM. Dominance hierarchies in group-living cleaning gobies: causes and foraging consequences. Anim Behav 2004;67:239-47.

[51] Jacob A, Nussle S, Britschgi A, Evanno G, Muller R, Wedekind C. Male dominance linked to size and age, but not to 'good genes' in brown trout (Salmo trutta). BMC Evol Biol 2007;7.

[52] Maruska KP, Fernald RD. Behavioral and physiological plasticity: rapid changes during social ascent in an African cichlid fish. Horm Behav 2010;58:230-40.

[53] Maruska KP, Fernald RD. Plasticity of the reproductive axis caused by social status change in an African cichlid fish: II. testicular gene expression and spermatogenesis. Endocrinology 2011;152:291-302.

[54] Schulz RW, Vischer HF, Cavaco JEB, Santos EM, Tyler CR, Goos HJT, et al. Gonadotropins, their receptors, and the regulation of testicular functions in fish. Comp Biochem Physiol B Biochem Mol Biol 2001;129:407-17.
[55] Wingfield JC, Hegner RE, Dufty AM, Ball GF. The challenge hypothesis theoretical implications for patterns of testosterone secretion, mating systems, and breeding strategies. Am Nat 1990;136:829-46.

[56] Oliveira RF, Ros AF, Goncalves DM. Intra-sexual variation in male reproduction in teleost fish: a comparative approach. Horm Behav 2005;48:430-9.

[57] Consten D, Keuning ED, Bogerd J, Zandbergen MA, Lambert JG, Komen J, et al. Sex steroids and their involvement in the cortisol-induced inhibition of pubertal development in male common carp, Cyprinus carpio. Biol Reprod 2002;67:465-72.

[58] Goos HJ, Consten D. Stress adaptation, cortisol and pubertal development in the male common carp, Cyprinus carpio. Mol Cell Endocrinol 2002;197:105-16.

[59] Tomkins JL, Lebas NR, Unrug J, Radwan J. Testing the status-dependent ESS model: population variation in fighter expression in the mite Sancassania berlesei. J Evol Biol 2004; 17:1377-88.

[60] Saraiva J, Pignolo G, Gonçalves D, Oliveira RF. Interpopulational variation of the mating system in the peacock blenny Salaria pavo. Acta Ethologica 2012;15: 25-31. 